\title{
MULTIPLE PERFORATIONS ALONG THE TRANSVERSE COLON AS A RARE PRESENTATION OF INTESTINAL BEHCET'S DISEASE: A CASE REPORT
}

doi: 10.1590/S1807-59322009001200016

Kemal Karakaya, ${ }^{\mathrm{I}}$ Mustafa Comert, ${ }^{\mathrm{I}}$ Gamze Numanoglu ${ }^{\mathrm{II}}$

\section{INTRODUCTION}

Behcet's Disease (BD) is a rare and lifelong disorder characterized by inflammation of blood vessels throughout the body. ${ }^{1} \mathrm{BD}$ is much more prevalent in countries along the ancient silk road from eastern Mediterranean countries to Eastern Asia. ${ }^{1,2}$ Some environmental factors are proposed for the etiology. ${ }^{3}$ Since Behcet's ${ }^{4}$ original description in 1937, many other manifestations have been added to the original triad. Diagnostic criteria for BD were defined by the international study group for $\mathrm{BD}$ in $1990 .{ }^{5}$ Although the etiology of $\mathrm{BD}$ is unknown, it is likely due to an autoimmune vasculitis in genetically predisposed individuals triggered by an infectious agent or other antigens. ${ }^{2,6} \mathrm{BD}$ mostly affects children and young adults between the second and fourth decades of life ${ }^{7}$. Those affected before the age of 25 years (early onset) and males have been shown to have more severe disease symptoms. ${ }^{8}$ Treatment of BD is usually palliative and symptomatic. Antibiotic, antiviral, corticosteroid, immunosuppressive and cytotoxic agents are used for treatment according to the symptoms. Unlike neuroBehcet's, entero-Behcet's causes intestinal perforation/ bleeding and some vascular lesions. ${ }^{9-11}$ The syndrome usually runs a relatively benign course with exacerbations and remissions.

Gastrointestinal involvement of BD is rare. ${ }^{9}$ Common gastrointestinal sites affected by BD other than the mouth

\footnotetext{
${ }^{\mathrm{I}}$ Department of General Surgery, Zonguldak Karaelmas University - Zonguldak, Turkey.

" Department of Pathology, Zonguldak Karaelmas University - Zonguldak, Turkey.

Email: karakayakemal@hotmail.com

Tel: 903722612776
}

are the ileocecal region and the colon. There are only a few studies reporting colonic perforations due to BD. In this article, we report a patient with BD who underwent an emergency operation for acute abdomen that developed secondary to multiple perforations of the transverse colon. The patient had a good response to surgical treatment followed by corticosteroids, immunosuppressant drugs and colchicine.

\section{CASE DESCRIPTION}

A 21-year-old man was admitted to the emergency department of our hospital complaining of severe abdominal pain, nausea, poor appetite and fever. Medical history revealed that five years ago he was diagnosed with BD because of his recurrent, painful oral and genital ulcers and positive pathergy test. Colchicine treatment was started and he was followed in an outpatient clinic. He had arthrosynthesis due to left knee arthritis two years after the diagnosis of $\mathrm{BD}$ while he was under colchicine therapy. Since then, he suffered several attacks of arthritis, and corticosteroid and nonsteroidal anti-inflammatory drugs were added. The patient had no family history of BD.

Physical examination revealed diffuse abdominal tenderness and rebound. Oral and genital examinations were normal. Abdominal ultrasonography revealed massive free fluid and thickness of the bowel wall.

An emergent laparotomy was undertaken on the patient. The peritoneal cavity was filled with purulent fluid. Swelling of the mesentery and thickness of the bowel wall, especially on the right side of the abdomen, was remarkable. During exploration, three separate perforations on the antimesenteric side in a $12-\mathrm{cm}$ segment of the right half of the transverse 
colon were observed. The involved segment was resected. The cut edges were free of ulceration on gross appearance. A double-barrel colostomy was performed on the right upper quadrant of the abdomen. Surgical specimen showed three perforations on the antimesenteric side of the colon. The perforations were $20 \mathrm{~mm}, 7 \mathrm{~mm}$ and $3.5 \mathrm{~mm}$ in diameter with a sharp margin of ulcer, a round, punched out figure (Figure 1). Postoperative course was uneventful. The patient was discharged on the fifth postoperative day. Histopathological analysis of the resected specimens demonstrated multiple round and ovoid mucosal ulcers with sharp margins, measuring up to $2 \mathrm{~cm}$ in maximal diameter. Many of these ulcers were penetrated or perforated and surrounded by extensive edema. Small venules and small arterioles in the submucosa and muscular layer of the entire colon segment were surrounded by extensive edema and diffuse mononuclear inflammatory cells (Figure 2).

Azathioprim was added to the patient's therapy. Endoscopic control of the upper and lower gastrointestinal tract revealed no ulceration three months after the operation.

The patient's colostomy was closed four months after the first operation under a semi-addisonian protocol. The postoperative period was uneventful, and the patient was discharged on the seventh postoperative day. He was

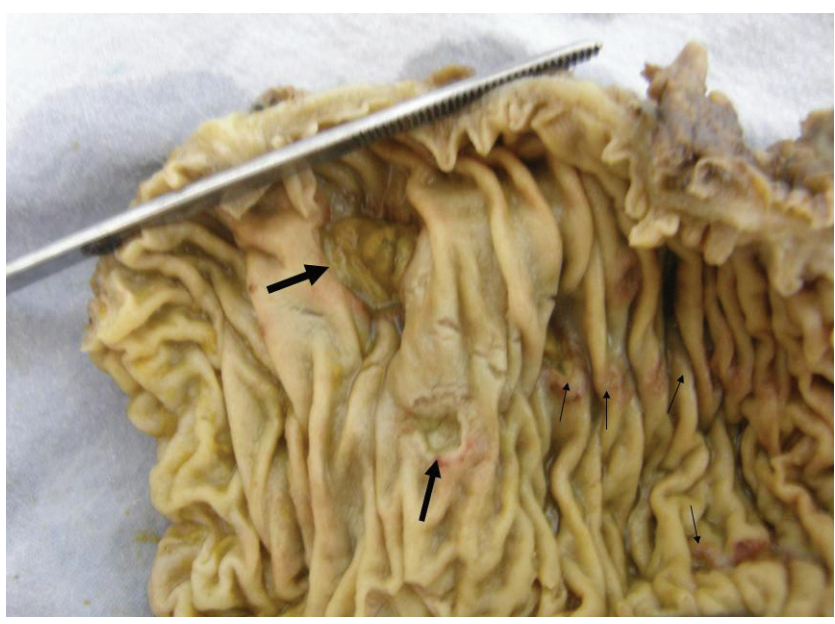

Figure 1 - Thick arrows indicate ulcers and thin arrows indicate macroscopic mucosal erosions

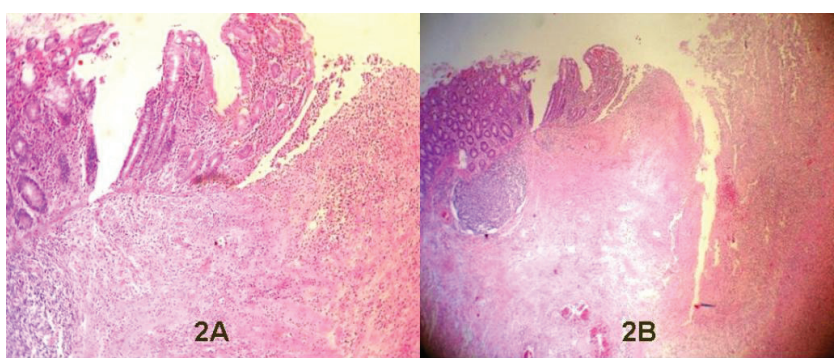

Figure 2 - (2A) Congestion, exudate and ulcer base with inflammation (H\&E x10). (2B) Perforation along whole thickness of the bowel wall with exuda and erosion (H\&Ex5) clinically well during the six-month follow-up period after the operation while taking colchicine and azathioprim.

\section{DISCUSSION}

Diagnosis of BD should be based on clinical criteria because there is no pathognomonic laboratory test to detect it. ${ }^{5} \mathrm{BD}$ may be seen at any level of the gastrointestinal tract. A common gastrointestinal site other than the mouth is the ileocecal region. ${ }^{12}$ Gastrointestinal symptoms related to BD are abdominal pain, nausea and vomiting. Some symptoms present in emergency conditions, such as intestinal perforation or bleeding. ${ }^{10,13}$ Intestinal lesions are located on the antimesenteric side (Figure 1).

Inflammatory bowel diseases should be kept in mind in the differential diagnosis of intestinal BD. The ulcers in intestinal BD may be aphtous or deep and round with a punched-out appearance. Although International Study Group criteria for BD accurately distinguish between BD and Crohn's Disease, ${ }^{14}$ there are some common features. Like Crohn's disease, BD manifests as discrete intestinal ulcers and discontinuous bowel involvement. Both of the diseases share extraintestinal manifestations, such as arthritis and uveitis. Rectal sparing is common for both. Longitudinal ulcers are rare in intestinal $\mathrm{BD}$, but common in inflammatory bowel diseases. The ulcers may cause penetration, perforation or bleeding. Multiple ulcers are generally seen at multiple sites and may resolve with medical therapy. Our patient had multiple ulcers that led to intestinal perforation in the transverse colon. The remaining intestines were considered normal in gross appearance at laparotomy. A wide range of hallmarks were apparent in this case suggesting that the patient had BD, including changes of the non-ulcerative mucosa, venulitis on the order of vasculitis, characteristics of ulcers, absence of lymphoid aggregates and granulomas in the bowel.

There was no ulcerative lesion determined by lower and upper GI endoscopy performed three months after surgery. It is also possible that intestinal ulcers might have healed with the corticosteroid and immunosuppressant agents added to the patient's therapy before endoscopic evaluation.

Treatment of BD is largely empirical, and a multidisciplinary approach is preferred. A multidisciplinary team should involve specialists in dermatology, rheumatology, ophthalmology, gastroenterology, immunology and others. Corticosteroids, immunosuppressants, and other agents such as colchicine and interferon are used for the treatment of BD.

Mesalazine and anti-tumor necrosis factors such as infliximab and thalidomide have been used for intestinal BD on a limited basis. ${ }^{15}$ The effectiveness of therapy on 
intestinal lesions is controversial because they can resolve spontaneously. ${ }^{16}$ Some reports state that corticosteroids may prolong the healing process and provoke perforations and pancreatitis. ${ }^{17}$ The recommended length of resection is controversial. Some authors advise wide surgical margins, while others recommend removal of only the grossly involved bowel. ${ }^{12,18}$ In another report, the length of resection did not affect the rate of recurrence or reoperation. ${ }^{12} \mathrm{We}$ preferred resection of the involved colon in our patient because the perforations were limited to a short segment of the proximal transverse colon. The patient received a corticosteroid (Prednisolone), immunosuppressant (Azathioprime) and colchicine together. No ulcers were apparent within the gastrointestinal tract three months after surgical resection. As the probability of recurrence after the operation due to intestinal perforation or penetration is higher, follow-up endoscopies are planned in an outpatient setting. In addition, studies with large series and long-term follow up are necessary.

In conclusion, practitioners should be aware of intestinal involvement of $\mathrm{BD}$, which accompanies ulceration of the intestine leading to perforation or hemorrhage. Colonic perforation is an unusual complication of $\mathrm{BD}$ and may occur anywhere in the colon without pioneering abdominal symptoms during the course of treatment. Urgent surgical resection is mandatory in case of colonic perforation. Successful surgical treatment would be expected with disease-free cut edges of the intestine.

\section{REFERENCES}

1 Barnes CG, Yazıcı H. Behçet's Syndrome. Rheumatology. 1999;38:11716.

2 Ebert EC. Gastrointestinal Manifestations of Behçet's Disease. Dig Dis Sci. 2009;54:201-7.

3 Zouboulis CC, Kotter I,Djawari D, Kirch W, Kohl PK, Ochsendorf FR, et al. Epidemiological features of Adamantiades-Behcet's Disease in Germany and in Europe. Yonsei Med J. 1997;38:411-22.

4 Behçet H. Über rezidivierende Aphthose, durch ein Virus verursachte Geschwüre am Mund, am Auge und an Genitalien. Dermatol Wochenschr. 1937;105:1152-7.

5 International Study Group for Behcet's Disease. Criteria for diagnosis of Behcet's Disease. Lancet. 1990;335:1078-80.

6 Barlas S. Behçet's disease. An insight from a vascular surgeon's point of view. Acta Chir Belg. 1999;99:274-81.

7 Koné-Paut I, Yurdakul S, Bahabri SA, Shafae N, Ozen S, Ozdogan H, et al. Clinical features of Behçet's disease in children: an international colloborative study of 86 cases. J Pediatr. 1998;132:721-5.

8 Yazıcı H, Tüzün Y, Pazarli H, Yurdakul S, Ozyazgan Y, Ozdo an H, et al. Influence of age of onset and patient's sex on the prevalance and severity of manifestations of Behçet's syndrome. Ann Rheum Dis. 1984;43:783-9

9 Pirildar T, Keser G, Tunç E, Alkanat M, Tunçyürek M, Do anav argil E. An Unusual Presentation of Behcet's Disease: Intestinal Perforation Clin Rheumatol. 2001;20:61-2.

10 Ketch LL,Buerk CA, Liechtey D. Surgical implications of Behçet's disease. Arch Surg. 1980;115:759-60.
11 Fujita H, Kiriyama M, Kawamura T, Ii T, Takegawa S, Dohba S, et al. Massive hemorrhage in a patient with intestinal Behçet's disease: report of a case. Surg Today. 2002;32:378-82.

12 Choi IJ, Kim JS, Cha SD, Jung HC, Park JG, Song IS et al. Long-term clinical course and prognostic factors in intestinal Behcet's disease. Dis Colon Rectum. 2000;43:692-700.

13 Yildirim M, Erkan N, Bayam E, Sahin T. An uneventful complication of Behcet's disease: Intestinal perforation. Chir Gastroenterol. 2006;22:524.

14 Tunc R, Uluhan A, Meliko lu M, Ozyazgan Y, Ozdo an H, Yazici H. A reassesment of the International Study Group criterianfor the diagnosis (classification) of Behcet's syndrome. Clin Exp Rheumatol. 2001;19 Suppl. 24:S45-7.

15 Sfikakis PP, Markomichelakis N, Alpsoy E, Assaad-Khalil S, Bodaghi B, Gul A, et al. Anti TNF therapy in the management of Behcet's diseasereview and basis for recommendations. Rheumatology. 2007;46:736-41. Epub 2007 Apr 2.

16 Takada Y,Saigenji K. Is intestinal Behcet's disease in fact an enterocolitis or an ulcer disease, and is steroid treatment useful or harmful?. J Gastroenterol. 2003;38:1015-16.

17 Toda K, Shiratori Y, Yasuda M, Enya M, Uematsu T, Shimazaki M et al. Therapeutic effectof intraarterial prednisolone injection in severe intestinal Behcet's disease. J Gastroenterol. 2002;37:844-8.

18 Kasahara Y, Tanaka S, Nishino M, Umemura M, Siraha S, Kuyama T. Intestinal involvement in Behcet's disease: Review of 136 surgical cases in the Japanese literature. Dis Colon Rectum. 1981;24:103-6. 